\title{
REVIEW OF GOUT, 1939-1946
}

BY

\author{
L. C. HILL
}

The main contributions to the subject of gout during the period under review have not unnaturally come from American workers. In spite of outstanding research by Talbott and Coombs (1938), Bauer and Klemperer (1942), and others into the metabolic and clinical aspects of the disease, the essential problem remains unsolved. Gout used not to be regarded very seriously by American physicians, and it is only during the last decade that it has been recognized as a not infrequent cause of arthritis.

\section{Incidence}

Hench's claim (1935) that patients with gouty arthritis constitute at least $5 \%$ of all patients seen at the Mayo Clinic suffering from joint disease was supported by Kahlmeter (1938), by Kinell and Haden (1940) in their review of 62 cases of gout, and recently by Wright (1945) in Canada. Experience of work in two rheumatic hospitals in this country leaves an impression that this proportion is certainly not too high, especially considering the number of cases of acute gout which never reach hospital but are treated privately, and also the atypical forms which, even with long experience and the full resources of the laboratory and $x$-ray department, are difficult to recognize. Whatever be the incidence, sufficient evidence is now available to prove that gout is not a rare disease, and if it is diagnosed less frequently in this country and in Europe nowadays than heretofore, this merely reflects more accurate diagnostic criteria.

\section{Heredity}

Recent work has strengthened the impression that gout is a hereditary disease, and has confirmed the statement of Futcher (1914) that a woman can transmit the diathesis to her offspring without herself developing the disease. The medico-sociological studies of Talbott and of Coombs (1938 and 1940) are very interesting. An exhaustive examination was made of 136 blood relatives of 27 patients with well established gout, none of whom had ever had an attack. A plasma uric acid of over $6 \mathrm{mg}$. per 100 c.cm. was found in $25 \%$, and of this number $80 \%$ were males. No alternative cause, renal or otherwise, could be found to account for the findings. These workers, therefore, conclude that the gouty constitution is a hereditary predisposition based on hyper-uricaemia, and they relegate social factors, environmental influences, and dietetic indiscretions to a position of secondary importance. A life-long follow-up would be necessary before it can be known what proportion of such affected relatives will later develop clinical gout. It is difficult to see much justification for Talbott's hypothesis (1946) that such hyper-uricaemia is due to increased production of uric acid in the body, but this point will be discussed later. Smyth and Freyberg (1942), in their study of the hereditary nature of gout, have approached the problem from the same direction, with similar results save that in their investigations they found no single female relative with a raised blood uric acid. In a big series, Bauer (1943) found a family history in $75 \%$ of patients. An additional allergic factor in the family history was claimed by Burt and Gordon (1939), and also by Mackay (1939) in some cases, but unfortunately no figures are quoted. This attractive hypothesis would account for the undoubted sensitiveness of many gouty patients to certain articles of diet and alcoholic beverages, an aspect which is much too lightly dismissed by the American workers.

\section{Metabolism}

The great majority of modern workers agree in classing gout as a metabolic disorder, though no clear evidence of any disturbance of the metabolism of purines and nucleo-proteins has been produced. There will be general agreement with Talbott (1946) that the term " urate " should replace " uric acid", since, in the serum and body fluids, $97 \%$ of uric acid is in the form of sodium urate. The terms " uric acid" and "urate" are used synonymously throughout this review.

No new facts are available from a study of the literature of the period to explain satisfactorily the main problems in gout-namely, the altered excretion of urate, the raised blood uric acid, and the deposition of urate in the tissues.

Blood Uric Acid.-Considerable difference of opinion exists with regard to the blood uric acid level in gout. In 900 tests on 100 patients with gout (in all stages of the disease), $98 \%$ were found by Talbott (1946) to have $6 \mathrm{mg}$. per $100 \mathrm{c.cm}$. or more in the serum, the average being 8.8 per $100 \mathrm{c.cm}$. This compared with the normal finding (less than $6 \mathrm{mg}$. per $100 \mathrm{c.cm}$.) in $96 \%$ of 400 non-gouty control tests. These are surprisingly high figures and do not accord with day-to-day experience, though the figure of $90 \%$ was quoted by the writer in a study of 93 cases of gout (Hill, 1938). Comparable figures are not readily available, but Bauer states that the blood uric acid levels are always inconstant and irregular. Coombs (1940), and Bauer and Klemperer (1942) support the thesis that the serum urate in gouty patients is above normal, in contrast to the 
constantly normal findings in all other arthritic conditions and most other morbid states. A further group of patients collected by Cohen of Philadelphia, and quoted by Talbott (1946) in his book on gout (p. 95), showed a level of $6 \mathrm{mg}$. per $100 \mathrm{c.cm}$. or over in all but 3 of 36 cases of clinical gout, and even these 3 had had at other times concentrations greater than $6 \mathrm{mg}$. per $100 \mathrm{c.cm}$. The failure of some physicians to have faith in a raised uric acid may be attributed, according to Talbott, to the selection of whole blood in preference to serum or plasma. This is stated to be less reliable because of the concentration of interfering substances in the red cells, which act in some cases by modifying colour development.

In the writer's personal experience values below $6 \mathrm{mg}$. per $100 \mathrm{c.cm}$. have from time to time been found in patients suffering from established gout, particularly during an acute attack, and this phenomenon was mentioned by Waterhouse (1938), whose long clinical and pathological experience of the subject merits attention The reasons for these discrepancies remain obscure. Kinell and Haden (1940) advise that too much dependence should not be placed on a raised blood uric acid, especially in the early stages. Cecil (1941) states that many patients with gout do not show a raised uric acid, especially in the acute stages of the disease.

Purine Metabolism.-Urate is the end-product of purine metabolism, and that excreted in the urine derives from both endogenous and exogenous sources. Research work by Bauer, Talbott, and others has confirmed Pommer's (1933) original figure of $300 \mathrm{mg}$. of urate excreted daily on a purinefree diet of adequate calorific value. This represents the endogenous portion. The exogenous urate is derived from foods with a high purine or nucleoprotein content, but as Wright (1945) states " to regard this as the underlying cause of gout is akin to asserting that carbohydrates are the cause of diabetes".

There is no conclusive evidence to support any of the three possible metabolic dysfunctions which might conceivably lead to increased concentration of urate in the blood or serum; i.e. (1) diminished destruction of urate by the body; (2) diminished excretion by the kidney; (3) increased formation by the body. Destruction of either endogenous or exogenous uric acid has never been proved in human beings, and no enzyme has ever been discovered in the body capable of initiating such destruction. Altered excretion of urate by the kidneys is the popular current explanation and is supported by, among others, Bauer (1943), Thannhauser (1929), and most modern writers on the subject; but the work of Coombs and his associates (1940) and of Talbott (1946) brings experimental evidence to show that there is no differential inability of the kidneys in gout to clear urate. These workers state that little difference exists between gouty and non-gouty persons in regard to renal exchange of urate, and that when urate reabsorption is interfered with by the action of such substances as atophan and salicylate, gouty and non-gouty persons respond in a similar manner. It is only when unmistakable signs of renal impairment are found that urate clearance is affected through a critical depression in glomerular filtration rate. Wright (1945) of Canada supports these views.

On the basis of a persistent increase in the total daily excretion of urate demonstrated in a group of gouty patients and also in non-affected relatives of gouty patients, Talbott (1946) believes an increased formation of urate to be the fundamental metabolic factor; but his arguments are not entirely convincing and he appears to arrive at this conclusion more by the process of elimination than by factual evidence. The occasional occurrence of gouty artl.ritis in patients with leukaemia and polycythaemia vera (Reifenstein, 1939; and Tinney and his co-workers, 1945), diseases which are known to be associated with hyper-uricaemia due to endogenous nuclear katabolism, is adduced as evidence to support this The numbers are, however, very small: in one series, only 8 out of 168 patients with polycythaemia vera over a period of several years, developed gout. Incidentally it was observed that the level of the blood uric acid was not proportional to the severity of the polycythaemia. It is to be noted that high uric acid levels are found in chronic nephritis, but the development of gout in such cases is extremely rare.

On the other hand Bauer and Klemperer (1942) postulate a selective deficiency in elimination not necessarily associated with demonstrable renal impairment.

Interesting work on the renal exchange of urate has been carried out by Smith (1937), and Smith and his associates (1938), and confirmed by Talbott (1946). They were able to measure the rate of formation and flow of glomerular filtrate and to note that the concentration of urate is similar to that found in plasma. Slightly more than $90 \%$ of the urate in the glomerular filtrate is reabsorbed by the tubules, as compared with over $98 \%$ of the fluid, with the result that the concentration of urate in bladder urine is several times greater. Urate clearance data in 28 gouty patients without obvious renal impairment showed no essential differences from those found in 55 non-gouty controls. Only when renal function is impaired to an extent capable of depressing glomerular filtration is retention of urate demonstrable. Recent work on the effect of drugs on urate clearance by Price (1945) and Coombs and his associates (1940) confirms earlier observations. Atophan and salyrgan appear to act by insulting the tubular epithelium, thus interfering with urate reabsorption, while salicylate diuresis is said to occur as a result of the preoccupation of tubular cellular activity in salicylate excretion to the detriment of urate reabsorption. Colchicine has no effect upon urate clearance. Its mode of action is entirely unknown.

\section{Morbid Anatomy}

In the period under review little if any fresh light has been thrown on the morbid anatomy of gout. 
The one distinguishing feature remains the deposition of urate in the tissues, both soft and bony, and the inflammatory and degenerative change resulting therefrom. Talbott (1943) believes that such deposition precedes the acute attack and takes place from the synovial fluid without previous necrosis. The theory, held by many, that the acute attack of gouty arthritis is caused by the bursting into the joint space of a uratic deposit, remains to be proved. The loss of bone in the area of urate deposition is probably due to local inhibition of osteoblastic activity, so that when the bone is normally absorbed, it is not replaced. Most of the anatomical variations observed in the late stages of gout are probably the results of arteriosclerosis, which in its turn is secondary to renal impairment. The varied terminology given to the renal lesions of gout indicates the lack of unanimity of opinion concerning the exact nature of the change, but the great majority of workers now agree that such changes are the result and not the cause of gout.

The effects of gout upon the cardiovascular and renal systems have formed a basis for discussion and argument for many years, but opinion that there is no direct relationship is strengthening. Recent work by Steinberg (1945) found no statistical evidence connecting gout with either angina, hyperpiesia, or renal calculus, while Koller and Zollinger (1945), exxamining the kidneys of 5 cases of gout, found a sclerotic condition-involving glomeruli, arteries, and interstitial tissue-which they consider similar to the changes found in diabetes.

\section{Clinical Aspect}

Conventionally the first sign of gout is an acute attack in a joint, and the diagnosis is usually not suspected until the attack has occurred. Prodromal symptoms have been widely described and formed an important part of the description of the disease, particularly among late nineteenth-century writers. Such premonitory symptoms include depression, insomnia, nightmares, flatulence, constipation, dyspepsia, anorexia, nausea, vomiting, and polyuria. According to Wright (1945), the majority of patients have no such symptoms, while a small percentage undoubtedly do. Talbott (1946) agrees with Wright, and considers that while many persons have premonitions of an impending attack, the majority of such symptoms are to be attributed to precipitating factors and are not an integral part of the acute attack. No subsequent description of the acute attack has excelled in vividness and simplicity that of Thomas Sydenham in 1717, written from personal experience. There is general agreement that the onset is usually at night and that the pain is intense, being variously described as "vice-like", as if " dipped in molten lead", etc. The pain appears to be caused by a rapid effusion into the joint space, with oedema of the surrounding tissues. Tenderness is a typical feature, and is usually maximal over the lateral aspects of the involved joint. As compared with an acute suppurative arthritis, the skin tends to be tense, shiny, and cyanotic, rather than fiery red. Acute attacks usually involve joints, but very occasionally non-articular structures are attacked, notably a subcutaneous bursa or the helix of the ear, in which case pain is much less severe. The site of the first attack is usually the metatarsophalangeal joint of the great toe. Talbott agrees with Scudamore (1823) that this is so in $60 \%$ of all cases, while other workers, including Bauer (1943), put the figure at $50 \%$. Treatment is the most important single factor in determining the duration of an attack. If adequate, it may abort a mild one and appreciably shorten the duration of a severe one. Prolongation of the acute phase may be caused in untreated cases by repeated small attacks, and this is more likely to occur in patients with advanced chronic gout. Most writers, including Cecil, Bauer, and Talbott, fix as a dividing-line between acute and chronic gout the stage when the joint fails to return to normal after an acute attack. There is also general agreement that the earlier the age at which the first attack occurs the more the likelihood that distribution will be polyarticular and that constitutional and chronic joint changes will develop. When gout develops over the age of fifty it is usually mild and the prognosis good.

Precipitating factors.-Indiscretions in eating and drinking have long been blamed for inciting acute attacks. Alcohol and purine-rich foods are particularly suspect, while certain specific foods have been claimed to produce acute attacks, supposedly by an allergic reaction. Talbott (1946) holds that "gout is an hereditary metabolic disease, relatively immune to incidental items such as food and drink. The presumption that particular foods are harmful to gouty patients is not an empiric observation. It is a prejudice". Bauer (1943), writing in the same vein, regrets that such teachings are shrouded in the semi-sanctity of a long and venerable heritage, and have never been subjected to experiment or analysis. If it is agreed-and the evidence is all in favour of it-that gout is a hereditary disease, then obviously dietetic factors cannot be causative. The whole position remains obscure. Certain workers, including Bauer (1943), have found that most gouty patients do not react to occasional excess purine feeding, and they also note that acute attacks over a period have not coincided with a high purine intake. It is an established fact that gout occurs occasionally in vegetarians. Talbott (1946), while virtually denying that alcohol in any form influences the disease, admits that in some cases a high purine diet does appear to initiate attacks. Burt and Gordon (1939) stress the sensitiveness of gouty patients to certain articles of diet or certain products of metabolism, and regard the acute attack as an allergic manifestation. This view is strongly supported by Mackay (1939), who considers that the hereditary element in gout is twofold, consisting of a gouty diathesis (presumably associated with a tendency to high serum uric acid) and an allergic diathesis. This second factor is not invariably 
present, but when it is it accounts for the sensitiveness to various items of food, etc. More universally accepted excitants of the acute attack include drugs, trauma, infections, and surgical operations. Attacks of gout have followed injections of liver (Herrick and Tyson, 1936; and Krafka, 1935), salyrgan, insulin, ergotamine tartrate, and vitamin $\mathbf{B}_{1}$ (Vorhaus and Kramer, 1938). The mechanism by which they act is variously described, but the case reports are too few to do more than suggest an association. That trauma (in whatever form), and acute infections are precipitators has been recognized from early times. Recently Hench (1940) has drawn particular attention to the significance of postoperative gout.

\section{Complications}

Renal disease.-Renal disease is the most serious complication. In a series of 77 autopsies on gout, Gudzent (1928) found only 4 showing no sign of renal disease. Bauer states that the majority of gouty patients die from uraemia. This has not been the writer's experience in practice, though it is probably true of those who die below the age of fifty-five. There will be general agreement with Hench's dictum (1940) that any chronic arthritis associated with renal disease is almost certainly gout. In two series of cases published by Talbott (1943), approximately $50 \%$ of patients showed an impairment of one or more renal functions, and Talbott believes that if additional tests had been performed the figures would have been still higher. He concludes that the majority of patients with gout, irrespective of age or duration of symptoms, have some impairment of renal functions. Coombs and his co-workers (1940) demonstrated some degree of renal impairment in a still higher percentage of patients with gout. They find that the most constant feature is the inability to concentrate solids maximally, and state that neither age nor duration of symptoms, nor the level of uric acid concentration, is the sole determining cause. They conclude that renal changes are always the result and never the cause of gout. On the other hand, Burt and Gordon (1939) maintain that chronic nephritis is not a common sequela of gout.

Vascular disease.-Arteriosclerosis and hypertension are stated by Talbott to occur more frequently in young gouty patients than in those in a similar age group suffering from other chronic diseases. In Talbott's series no instance of malignant hypertension was seen, all cases being of the benign type. $\mathrm{He}$ argues against any close association between hypertension and renal disease in gout. Coombs and his associates, and Bauer, on the other hand, found that in their series of patients with renal impairment over $40 \%$ either had or later developed benign hypertension. In their opinion this hypertension is arteriosclerotic in type and is secondary to prolonged renal damage and reduced renal flow. They state that when it occurs in gout it is a late manifestation. Steinberg (1945) found no evidence to support a connexion between gout and angina or hyperpiesia.

Urinary Calculi.-According to Hench, writing in 1940 (and quoted by Bauer in 1943) urinary calculi are relatively common in gouty patients: he found them in $12 \%$ of his series. Talbott (1943) mentions 4 patients in whom renal colic was the presenting symptom, preceding the first acute attack by a year or more. He considers it a rare complication. It is reasonable to agree with Bauer (1943) that when an arthritis is associated with urinary stone it is probably gout. At one time or another virtually every part of the body has been stated to be involved in the ravages of gout, but often the evidence is extremely slight. Talbott is reluctant to call any complication gouty unless it is associated with urate deposition or has a high incidence in gouty patients. Gundeson (quoted by Talbott, 1946), in a series of 30 consecutive cases, was unable to observe by slit lamp any traces of urate crystals in the lens, and so he could not confirm Weve's original findings (1924). In a much larger series Talbott found no disproportionate occurrence of skin lesions, psoriasis, or eczema. He did note, however, that those who had these conditions reported that they tended to flare up during acute attacks. Bauer agrees with this, and considers that all these conditions are probably unrelated to gout.

\section{Associated Diseases}

The association of gout with lead poisoning has been stressed for a generation or more, particularly in England and in Germany, where in a big series of cases of lead poisoning Strierlin (1932) found $3 \%$ to be suffering from gout. The association appears to be rare in the U.S.A., Talbott (1946) finding only one case of lead poisoning in his large series. There is no ready explanation for the discrepancy between European and American data. In the writer's opinion the frequency of the association has been over-stated in this country, and he found no single case of lead intoxication in his series of 93 cases. In fairness to the older British physicians it must be admitted that the association is naturally more infrequent to-day, since lead poisoning is now rare. This is discussed in Allbutt's System of Medicine (1897), and also by Allbutt and Rolleston (1907). There will be little tendency to disagree with Talbott or Bauer when they deny any connexion between gout and diabetes, but few will associate themselves with Talbott when he states that the majority of his gouty patients are not obese. Kinell and Haden (1940) in their review of 62 cases, take the traditional view when they state that gout appears typically in obese, healthy-looking middleaged men engaged in sedentary occupations, and Wright (1945) agrees with them.

It is generally admitted that gout and leukaemia can coexist. Talbott considers the association very rare, having met with it only once. Reifenstein (1939) observed a patient over a five-year period, 
who presented himself with symptoms of polycythaemia and a blood uric acid of $5 \cdot 3 \mathrm{mg}$. per 100 c.cm., and who subsequently developed gout and later myeloid leukaemia. Tinney and his coworkers (1945), as stated before, have made a very complete study of polycythaemia, and report that in 8 out of 168 patients the disease was associated with gout. They state that the coexistence renders mild gout severe, and severe gout difficult to control. In these combined cases the uric acid level was not proportionately higher. Lambie (1940) reports a case of chronic erythronoclastic anaemia in which gout developed. Acute attacks of gout have followed intense liver therapy and large doses of vitamin $B_{1}$ (Wright, 1945; Talbott, 1946; Herrick and Tyson, 1936; Krafka, 1935; Vorhaus and Kramer, 1938).

\section{Diagnosis}

Talbott (1940) considers that gout may be suspected, even before the first acute attack, when, acting on the evidence of a strong family history, the serum uric acid is found to be raised. The suspicion is strengthened if the patient passes a urinary calculus. After the development of an attack in the joints, additional evidence may be obtained from the therapeutic response to colchicine, the finding of a tophus, and signs of renal impairment. In the first years after the onset of an acute attack radiological examinations are usually negative apart from a hazy appearance from soft tissue swelling (Kamberg, 1943). Punched-out areas in the subchondral region represent foci of sodium urate deposition, and lead to a worm-eaten appearance. They usually appear late and are not pathognomonic, since they may occur also in rheumatoid arthritis. Talbott states that to diagnose gout from a punched-out area is as unreliable as to exclude it because the radiological findings are negative.

The Sedimentation rate.-The sedimentation rate of the red cells is not usually regarded as a particularly useful test in the diagnosis of gout. Wright (1945) states that it is usually increased during acute exacerbations. Haden and Kinell (1942) found that it was raised in 87 of 100 cases of gout, with an average level of $0 \cdot 94$. This compared with a level of 0.24 in 50 normal controls, 0.58 in 100 osteo-arthritic, and 0.98 in 100 rheumatoid arthritic patients. These authors state that the sedimentation rate quickly returns to normal after an acute attack, and is generally highest in the chronic progressive stage of gout. No relation was found between the sedimentation rate and the level of the blood uric acid. These findings accord with general experience, though the rate reported appears unexpectedly high. The writer has also noted a tendency for the blood sedimentation rate to return rapidly to normal as an acute attack subsides, and this fact may assist in the diagnosis of atypical cases. The application of the therapeutic test with full doses of colchicine is now universally advocated. The results may be spectacular, but only if full doses are given. Talbott (1946) warns that inadequate doses may mislead. Lockie (1939), agreeing with this, also thinks that the low-carbohydrate, lowprotein, high-fat diet is a useful provocative test, and he quotes success in nine out of ten experiments. This is in direct contrast to the findings of Kersley and Gibson (1938) when they experimented unsuccessfully with ketogenic diets.

\section{Prognosis}

Most writers agree that, while the disease progresses in all patients after the first acute attack, the rate of progression is an unknown quantity. The more frequent and more severe the attacks, the more rapid the development of chronic permanent changes. It seems clear, too, that the younger the patient the greater the degree of crippling. Talbott has not seen a single case in which, if the first attack occurred over the age of fifty, serious polyarticular lesions developed. Expectation of life depends upon the degree of renal impairment. A patient may live for many years with advanced joint disease, but only a short time with severe kidney damage.

\section{Treatment}

Gout is incurable. If we accept a hereditary basis, then the problem of prevention is a eugenic one. Where there is a strong family history, possible precipitating factors (alcohol, dietetic indiscretions, sedentary life, etc.) should be avoided.

No new therapeutic discoveries emerge from a study of the literature. Colchicine in adequate doses is now universally used. Controversy rages round the toxicity of cinchophen, the relative values of low-fat or low-purine diets, the value of exercise or rest, and the effects of alcohol in its various forms. Talbott (1942) stresses the importance of an abundant fluid intake to combat dehydration (due to sweating and diuresis) and to allay precipitation of urate in the kidneys. Broths, fruit juices, and milk-fluids which contain minerals as well as calories-should be given. Most writers follow tradition in advocating strict reduction in purines. Bartels (1939) strongly recommends a low-purine, low-fat, high-carbohydrate diet both during and in between attacks, and so supports the earlier claims of Lockie and Hubbard (1934). Extra vitamins are added to make up for the deficiencies in A, D, and $B_{1}$. Bauer and Klemperer (1942) state on the other hand that omission of fat has not appeared to them beneficial, that high-fat diets have not precipitated attacks, and that the amount of fat contained in a well-balanced diet is insufficient to cause any significant retention of uric acid. Conclusive evidence is lacking, and opinions on this point vary widely.

There is little evidence in past or present literature to support the need for purine restriction. In a group of patients Talbott (1942) found that a measured low-purine diet had no effect on the frequency or severity of acute attacks. In the uncertain state of knowledge it seems reasonable to follow Talbott in advocating, according to tradition, a high-carbohydrate, soft diet for the acute attack, and a low-purine, normal-protein, moderate-fat, and high-carbohydrate diet in the intervening 
periods. For the acute attack the value of colchicine is established, and it is generally agreed that dosage must be pushed to the point when it produces gastro-intestinal irritation. Buckley (1937) always prescribes it with ext. hyoscyamus to prevent griping. Its usefulness in the intervals between acute attacks, in doses varying from two $\frac{-1}{2} \frac{1}{0}$-grain tablets per week to two per day, is more controversial. It is strongly recommended by Talbott (1942) and Steinberg (1945), but Bauer and Klemperer (1942) deny any value for it as a preventive measure.

The use of urate diuretics between attacks continues to be advocated, and there are rival claims for cinchophen on the one hand and salicylates on the other. Most American workers dislike cinchophen and consider it dangerous. Jennings (1937) was among the first to establish by original work the value of salicylate, and among others Talbott, Bauer, and Klemperer consider that it is as effective as cinchophen. Many writers, including Kersley (1946) in this country, and Wright (1945) in Canada, consider that the risks of cinchophen, while admittedly real, have been overrated, and advocate its use when salicylate fails to produce the desired effect.

\section{REFERENCES}

Albutt, T. C. (1897). System of Medicine, 1st ed., 3, 183, London. - and Rolleston, H. (1907). Ibid., 2nd ed., 3, 126, London.

Bartels, Elmer C. (1939). New Engl. J. Med., 220, 583.

Bauer, W. (1943). New Engl. J. Med.. 229, 583. and Klemperer, F. (1942). In Diseases of Metabolism. and Klemperer, F. (1942). In Diseases of Metabolism. Buckley, C. W. (1937). Br. Encyclop. Med. Pract. London. Article Buckley, C. W. (1937).

Burt, J. B., and Gordon, R. G. (1939). Annals of the Rheumatic Diseases, 1, 304

Cecil, R. L. (1941). N.W. Med.. 40, 411

Coombs, F. S. (1940). Ohio State med. J., 36, 951

Pecora, L. J., Thorogood, E., Consolazio, W. V., and Talbott, J. H. (1940). J. clin. Invest., 19, 525.

Futcher, T. B. (1914). Modern Med. [Osler and McCrae.] Article on Gout. 2nd ed., vol. 2. Appleton. Philadelphia.
Gibson, A. G. (1941). Practitioner, 147, 481.

Gudzent, F. (1928). Gicht und Rheumatismus. Springer. Berlin. Gundeson, T. (1946). Gout. [Oxford Medical Publications.] Quoted by Talbott, J. $\mathbf{H}$.

Haden, R. L., and Kinell, J. (1942). J. Lab. clin. Med., 27, 725.

Hench, P. S. (1935). Med. Clin. N. Amer., 19, 551. (1940). In Modern Medical Therapy in General Practice, edit. D. P. Barr. Williams and Wilkins. Baltimore.

Herrick, W. W., and Tyson, T. L. (1936). Amer. J. med. Sci., 192 483.

Hill, L. C. (1938). Lancet, 1, 826.

Jennings, G. H. (1937). Reps. on Chronic Rheum., 3, 106.

Kahlmeter. G. (1938). Proc. Internat. Congress on Rheumatism and Hydrology (London and Oxford) and Bicentenary Congress on Chronic Rheumatism (Bath), p. 298. Headley Bros. London.

Kamberg, S. (1943). N. Caroline med. J., 4, 219. Kersley, G. D. (1946). Br. Encyclop. med. Prac. "Interim Supple. ment " 41, March, 1946, p. 12

Kinell, and Gibson, H. J. (1938). Med. Pr., 196, 353

Kinell, J., and Haden, R. L. (1940). Med. Clin. N. Amer. 24, 429.

Koller, F., and Zollinger, H. U. (1945). Schweiz. med. Wschr., 75, 97.

Krafka, J. (Jr.) (1935). J. Bone Jt. Surg., 1935, 17, 1,049.

Lambie, C. G. (1940). Med. J. Austral., 1, 535

Lockie, L. Maxwell (1939). Ann. intern. Med., 13, 755. and Hubbard, R. S. (1934). Proc. Amer. Assoc. Study and
Control Rheum. Dis., 1, 96.

Mackay, W. J. Stewart (1939). Med. Pr., 201, 528; 546; 570.

Pommer, G. (1933). Beitr, path. Anat allgem. Path. 90, 513.

Price, N. Lloyd. (1939). Lancet, 1, 22.

Reifenstein. G. H. (1939). Amer. I. med. Sci., 197, 215

Scudamore, C. (1823). A Treatise on the Nature and Cure of Gout.

4th ed. London.
Smith, H. W. (1937). The Physiology of the Kidney. London U. P. Goldring, W., Chasis, H., and Ranges, H. A. (1938). Amer. J. Physiol., 123, 189.

Smyth, C. J., and Freyberg, R. H. (1942). Ann. intern. Med., 16, 46. Steinberg, G. L. (1945). Annals of the Rheumatic Diseases, 4, 51. Strierlin. (1932). Quant. Clin. Chem. Methods. Williams and Wilkins Co., Baltimore. Quoted by Peters and Van Slyke.

Sydenham, T. (1717). The Whole Works of that Excellent Practical Physician, Dr. Thomas Sydenham, translated by John Pechy. 7 th ed. Feales, London.

Talbott, J. H. (1940). J. clin. Invest., 19, 645.

- (1941). Rocky Mountain med. J. 38, 186.

(1942). Bull. N.Y. Acad. Med., 18, 318.

(1943). Gout, in Stieglitz, E. J., Geriatric medicine. Saunders and Co. Philadelphia. and Co. Philadelphia.

1946). Gout. Oxford Medical Publications. London.

-, and Coombs, F. S. (1938). J. clin. Invest. . 17, 508. Stoff, S. J. (1929). Lehrbuch des Stoffwechsels und der Stoffwechselkrankheiten. Bergmann. Munich.

Tinney, W. S., Polley, H. F., Hall, B. E., and Griffin, H. Z. (1945). Proc. Mayo Clin., 20, 49

Vorhaus, M. G., and Kramer, M. L. (1938). Trans. Amer. Therap. Soc.. 38, 109.

Waterhouse, R. (1938). Bicentenary Congress of Rheumatism Bath. London.

Weve, H. J. M. (1924). Over keratitis urica en andere vormen van jichtig ooglijden. Van Hengel. Rotterdam.

Wright, H. P. (1945). Canad. med. Ass. J., 52, 74. 